\title{
Accessibility-Based Location Selection for Building Panelized Housing for Seniors
}

\author{
Yuan Chen ${ }^{1 *}$, Xianfei Yin $^{2}$, Ahmed Bouferguene ${ }^{3}$, Yuxuan Zhang ${ }^{2}$, Mohamed Al-Hussein ${ }^{3}$, and \\ Bingsheng $\mathrm{Liu}^{4}$ \\ ${ }^{1}$ PhD candidate, Department of Civil and Environmental Engineering, University of Alberta \\ ${ }^{2}$ PhD student, Department of Civil and Environmental Engineering, University of Alberta \\ ${ }^{3}$ Professor, Department of Civil and Environmental Engineering, University of Alberta \\ ${ }^{4}$ Professor, College of Management and Economics, Tianjin University \\ "Corresponding author's e-mail: ychen10@ualberta.ca
}

\begin{abstract}
Population ageing is stimulating an increase in the demand for housing suitable for seniors. To meet the demand, the market share of senior housing needs to increase substantially in a relatively short period of time; therefore, panelized construction, as an efficient, economical, and environmentally-friendly construction method, can be regarded as a promising building approach to meet urgent demand for multi-unit housing. However, prior to construction, decisions regarding the location selection for building panelized housing can have a great influence on the level of accessibility that seniors have to neighbouring facilities and services, further affecting their health and quality of life. Based on this, the research presented in this paper aims to search potential land areas for panelized housing developments for seniors from the perspective of accessibility. A set of methods is proposed to define the opportunities and constraints for potential land, measure the accessibility, and select the most suitable location for senior housing by means of suitability analysis. A case study of Edmonton is then analyzed to illustrate the application of these methods.
\end{abstract}

\section{KEYWORDS}

Accessibility; Age-friendly urbanization; Geographic information system (GIS); Location selection; Panelized construction

\section{INTRODUCTION}

Population ageing, an unprecedented challenge related to the increase in the population of seniors, is confronting many countries, especially in relation to changes in housing design and demand (Chen et al., 2018a; 2018b). To boost market share of senior housing, automation approaches can be considered in the construction process (Balaguer et al., 2002; Bock, 2015). Furthermore, panelized construction is a good choice to build this type of housing in North America since this construction technique is efficient, economical, and environmentally-friendly (Li et al., 2017). Meanwhile, it breaks down the wood panels in walls, floors and roofs in manufacturing processes instead of on-site stick built, further improving productivity and reducing waste and pollutant emission (Liu et al., 2015). However, before proceeding with panelized construction, the critical point of the planning process is to select a proper location for 
building senior housing. In fact, appropriate housing and good access to facilities and services can have a great influence on seniors' independence and quality of life (WHO, 2007). Therefore, it is necessary to guarantee that the area neighbouring the panelized housing can provide seniors with various transportation options and access to facilities and services while also avoiding some factors in the environment that have potentially adverse influences on their health and life. To address the issue, a set of methods are proposed in this study to define opportunities and constraints for potential land selection, and select the most suitable location for building senior housing from the perspective of accessibility. It aims to provide the basis for urban planning strategies and a scheme for addressing the population ageing issue, making senior housing in a neighbourhood more age-friendly, giving suggestions to developers on housing location selection, and facilitating a more resilient lifestyle for seniors.

\section{METHODS}

Accessibility is generally described as the ease with which people can arrive at destinations (Hansen, 1959), which is largely influenced by transportation impedance measured by travel time or distance (Koenig, 1980; El-Geneidy et al., 2016). Since mobility is dependent on the person's skills and abilities as well as environment challenges (Frank and Patla, 2003), these factors will affect the time seniors spend walking on a certain route. Therefore, in the present study, travel distance is directly used as the index to measure accessibility if assuming one type of facility selected exists surrounding the panelized housing to build. Based on this, the framework of methodology is presented in Figure 1, which aims to clearly illustrate the relationship between research method and research objects, and show how to apply the research method to other regions for developing panelized housing for seniors from the accessibility perspective. Geographic information system (GIS) is the main tool utilized to realize our research objectives.

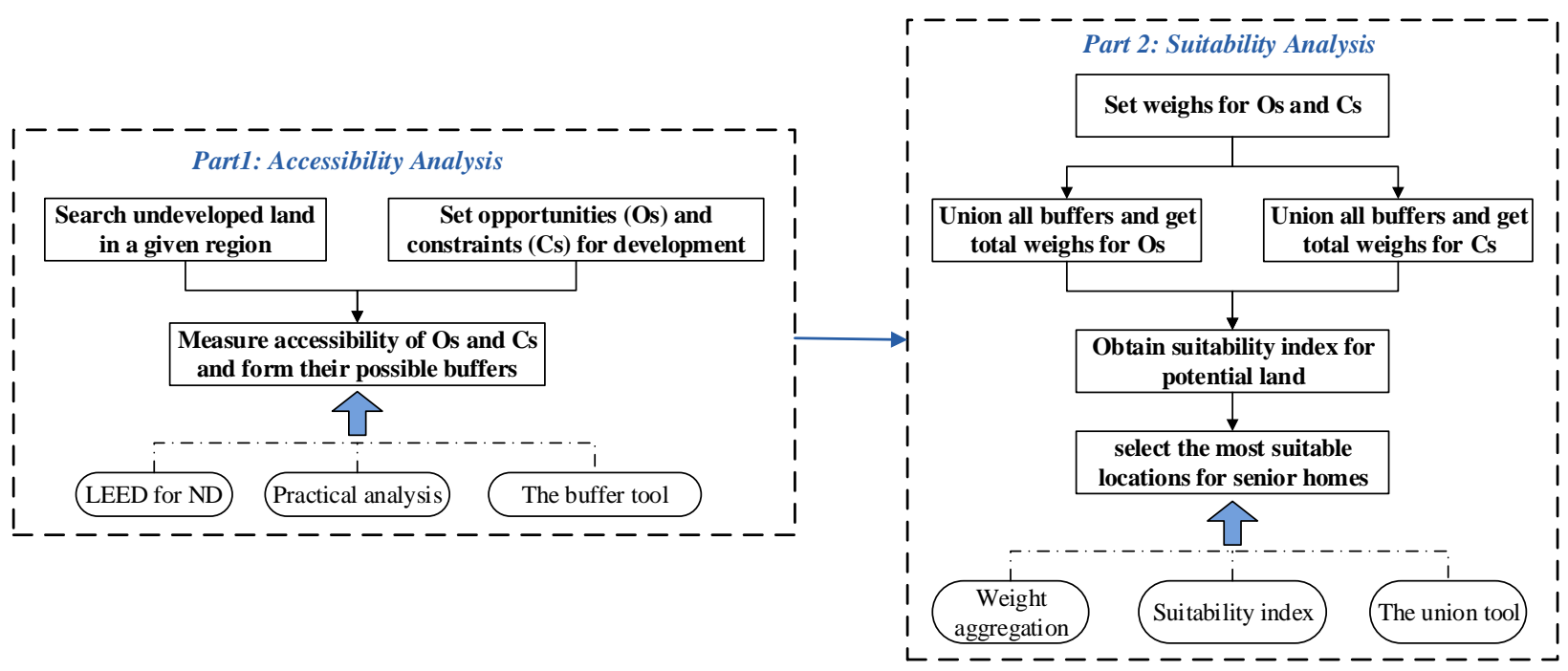

Figure 1. The methodology framework.

In terms of the accessibility analysis, opportunities and constraints for undeveloped land are considered: the accessibility of an opportunity refers to the areas surrounding the opportunity (e.g., bus stops) where senior housing can be developed, while the accessibility of a constraint 
(e.g., noisy streets) indicates the areas surrounding the constraint where the development of housing for seniors should be avoided. In the process, the buffer function in GIS is used to search the possible areas satisfying the corresponding distance thresholds. Generally, these thresholds are developed on the basis of related regulations and expert opinions. Leadership in Energy and Environmental Design for Neighborhood Development (LEED for ND) provides detailed neighbourhood development criteria for both the built projects and their planning (U.S. Green Building Council, 2016). It encompasses a set of rating systems for the design, construction, operation and maintenance of green neighbourhoods (Boeing et al., 2014). Hence, this study will refer to these standards in LEED for ND as part of basic thresholds for some of the opportunities and constraints.

In part 2, the suitability analysis supported by the union tool in GIS aims to select the most suitable locations for senior housing. Assume $w_{i}$ is the positive weight for the buffer of opportunity $i$, and $w_{j}$ is the negative weight for the buffer of constraint $j$. The weight is the importance degree graded by experts, so the analytic hierarchy process (AHP) method proposed by Saaty (1977) can be used to set the values of all weights. Then, we can obtain the cumulative weights for all buffers of opportunities and constraints and further yield the suitability index for potential land as Eq. (1)-Eq.(3). As a result, the most suitable locations for senior housing are derived from the larger value of the suitability index.

$$
\begin{gathered}
\text { Opportunity }=\sum_{1}^{n} w_{i} \\
\text { Constraint }=\sum_{1}^{m} w_{j} \\
\text { Suitability Index }=\text { Opportunity }+ \text { Constraint }
\end{gathered}
$$

\section{RESULTS AND DISCUSSION}

\section{Data description}

The segment of the population aged 55 and over in Edmonton, the capital of the province of Alberta, accounted for approximately $21 \%$ of the population in 2006, and this number is projected to grow to almost 32\% by 2041 (City of Edmonton, 2010). Therefore, the city is a great potential market for developing panelized housing for seniors. This paper will select Edmonton as a case to explore the potential location for the development of senior housing from the perspective of accessibility. The data sources are mainly comprised of undeveloped land, opportunities and constraints for senior home development, which come from Edmonton's Open Data Portal (EODP, 2018) and the locations of 18 Emergency Medical Services (EMS) stations in Edmonton from Alberta Health Services (AHS, 2018).

\section{Selection of opportunities and constraints}

The areas neighbouring senior housing is age-friendly, which aims to shape the neighbourhood for seniors in a way that promotes physical and mental wellness by ensuring good accessibility to neighbouring facilities and services. Also, the location of senior housing should avoid certain areas that may bring seniors some potential risk and injury. Based on this, opportunities and 
constraints for developing senior housing are listed in Table 1. The values of distance shown are used as the thresholds in the buffer tool; and the 1-5 scale rank is used to give weight to the degree of importance of opportunities and constraints. Researchers and practitioners can add more opportunities and constraints according to data availability.

Table 1. Opportunities and constraints for developing senior housing.

\begin{tabular}{|c|c|c|c|c|}
\hline \multicolumn{2}{|l|}{ Opportunity } & Distance $(\mathrm{m})$ & Weight & Reason \\
\hline \multirow{2}{*}{ Transit } & LRT stations & 400 & 3 & \multirow{2}{*}{$\begin{array}{l}\text { Ensure good access to public } \\
\text { transportation }\end{array}$} \\
\hline & bus stops & 400 & 4 & \\
\hline $\begin{array}{l}\text { Outdoor } \\
\text { space }\end{array}$ & parks & 400 & 4 & \multirow{2}{*}{$\begin{array}{l}\text { Provide seniors with areas for } \\
\text { entertainment and healthy } \\
\text { keeping }\end{array}$} \\
\hline Recreation & recreation centers & 800 & 3 & \\
\hline $\begin{array}{l}\text { Health } \\
\text { services }\end{array}$ & EMS stations & 6,250 & 3 & Ensure timely EMS \\
\hline \multirow[t]{2}{*}{ Security } & $\begin{array}{l}\text { front yards in } \\
\text { bloom awards }\end{array}$ & 500 & 2 & \multirow{2}{*}{$\begin{array}{l}\text { Maintain senior housing located } \\
\text { in a safer neighbourhood }\end{array}$} \\
\hline & fire stations & 6,000 & 3 & \\
\hline \multicolumn{2}{|c|}{$\begin{array}{l}\text { Areas with higher senior ratio } \\
\text { (ratio } \geq 10 \% \text { ) }\end{array}$} & & 2 & $\begin{array}{l}\text { Keep more seniors living in a } \\
\text { relatively familiar circumstance }\end{array}$ \\
\hline \multicolumn{2}{|c|}{ Constraints } & Distance $(\mathrm{m})$ & Weight & Reason \\
\hline \multicolumn{2}{|l|}{ Main streets } & 400 & -3 & $\begin{array}{l}\text { Avoid close to streets with large } \\
\text { traffic volume due to higher } \mathrm{CO}_{2} \\
\text { emissions }\end{array}$ \\
\hline \multicolumn{2}{|c|}{ Graffiti locations } & 400 & -2 & Avoid potential unsafe areas \\
\hline \multicolumn{2}{|c|}{ Mosquitoes trap locations } & 500 & -2 & $\begin{array}{l}\text { Avoid possible breeding grounds } \\
\text { for summer insects due to } \\
\text { senior's physical condition }\end{array}$ \\
\hline \multicolumn{2}{|c|}{ Water source (lake or river) } & 400 & -1 & $\begin{array}{l}\text { Proximity to water, breeding } \\
\text { ground for all kinds of pests, } \\
\text { unsafe for seniors (e.g., falling } \\
\text { and drowning) }\end{array}$ \\
\hline
\end{tabular}

\section{Location selection for senior housing}

Population ageing (i.e., the ratio of seniors in the total population) is analyzed at the neighbourhood level, with a total of 386 neighbourhoods in Edmonton. However, not all neighbourhoods have demographical information available, such as areas for industry, nature, and transportation. Based on this, we need to do data preprocessing, evaluate the degree of population ageing in each neighbourhood, and search the undeveloped land in Edmonton for suitable locations for senior home development. The results are shown in Figure 2. Some areas of undeveloped land are too small in the figure, so it is shown in the form of dark spots. Population ageing is distributed as a radiation pattern, with a higher degree concentrated in the center of this city, while the degree tends to decrease farther away from the center. The highest degree of population ageing is slightly more than 0.5 in some neighbourhoods, while the average degree is around 0.15. The undeveloped land in the center of this city is distributed as a higher density of smaller areas, while several blocks of land near the city boundary are undeveloped and represent a large area. 


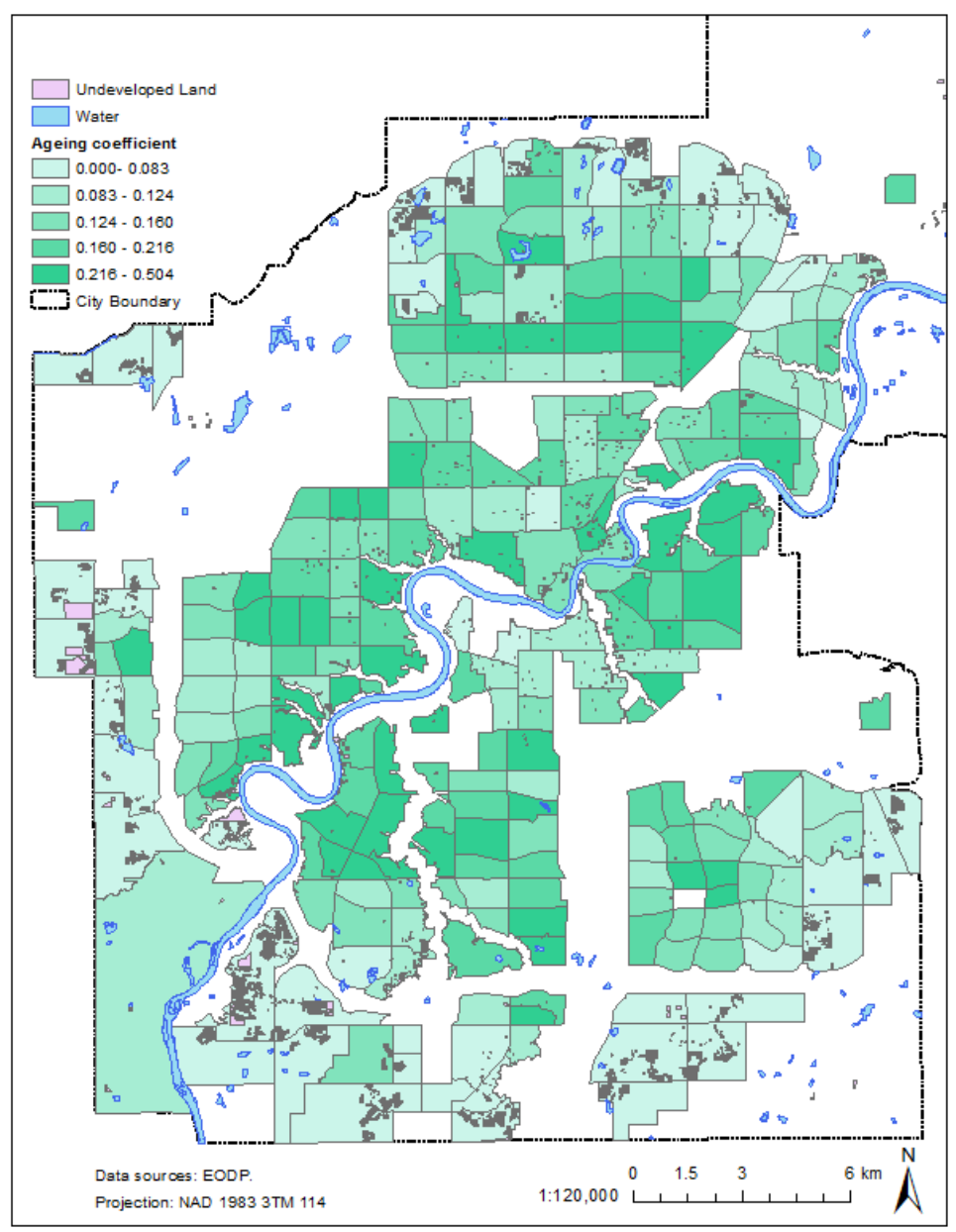

Figure 2. Potential land for developing panelized housing for seniors.

Based on Table 1 and Eq. (1)-Eq. (2), the buffer function in GIS is used to search the possible areas for the opportunities and constraints within the distance thresholds. Then, the integrated areas for opportunities and constraints are formed and their corresponding cumulative weights are displayed in Figure 3 and Figure 4, respectively. O_Total refers to the cumulative weights for opportunity buffers, and their average value is 14 . These opportunity areas are mainly located in the central part of this city along the river, while the undeveloped land near the boundary does not have an obvious competitiveness. The higher value of C_Total in Figure 4 means that it is more unsuitable to develop senior housing in these areas. By using the union function in GIS and Eq. (3), the more suitable locations for senior housing can be found in Figure 5, where the suitability index of these locations is ranked in the top three. It can be seen that these areas are mainly located in the eastern center of this city south of the main river. Seniors living in these communities have good access to green space, since park density there is much higher. Also, more street paths and transit choices are provided for older adults, which enhances relatively convenient travel within and across neighbourhoods. Furthermore, a variety of recreation facilities surround these areas, so seniors are equipped with multiple options entertainment. 


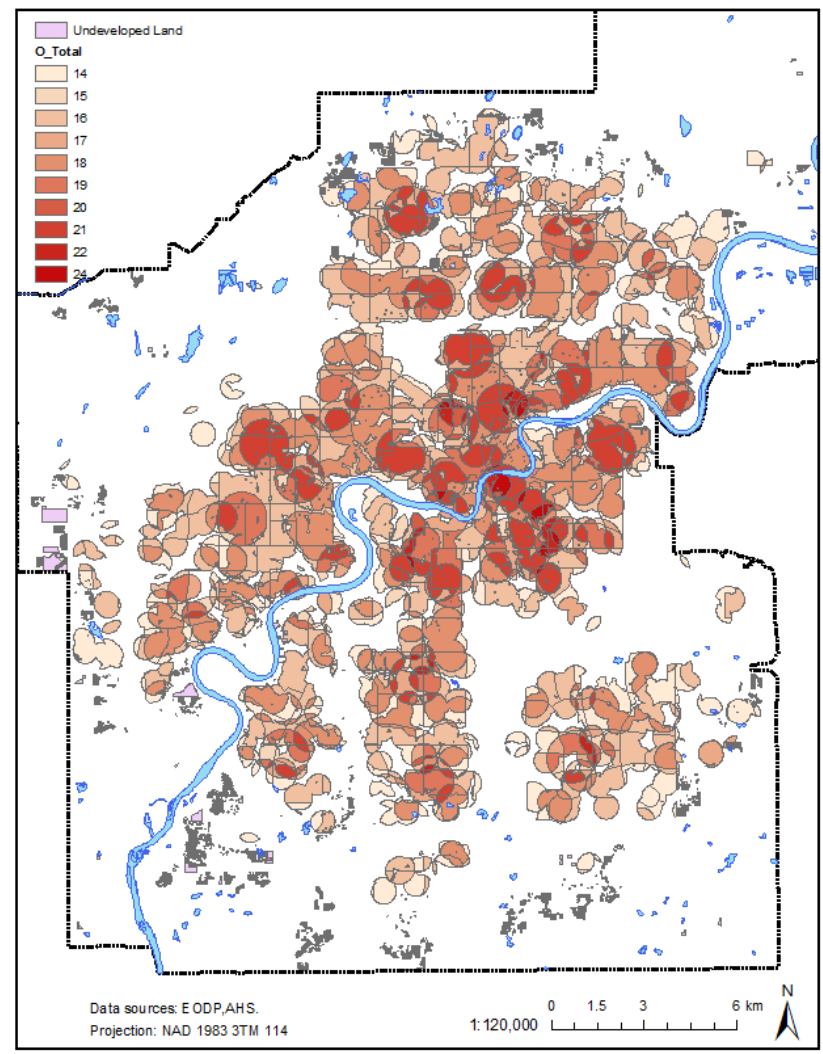

Figure 3. Distribution of opportunity buffers.

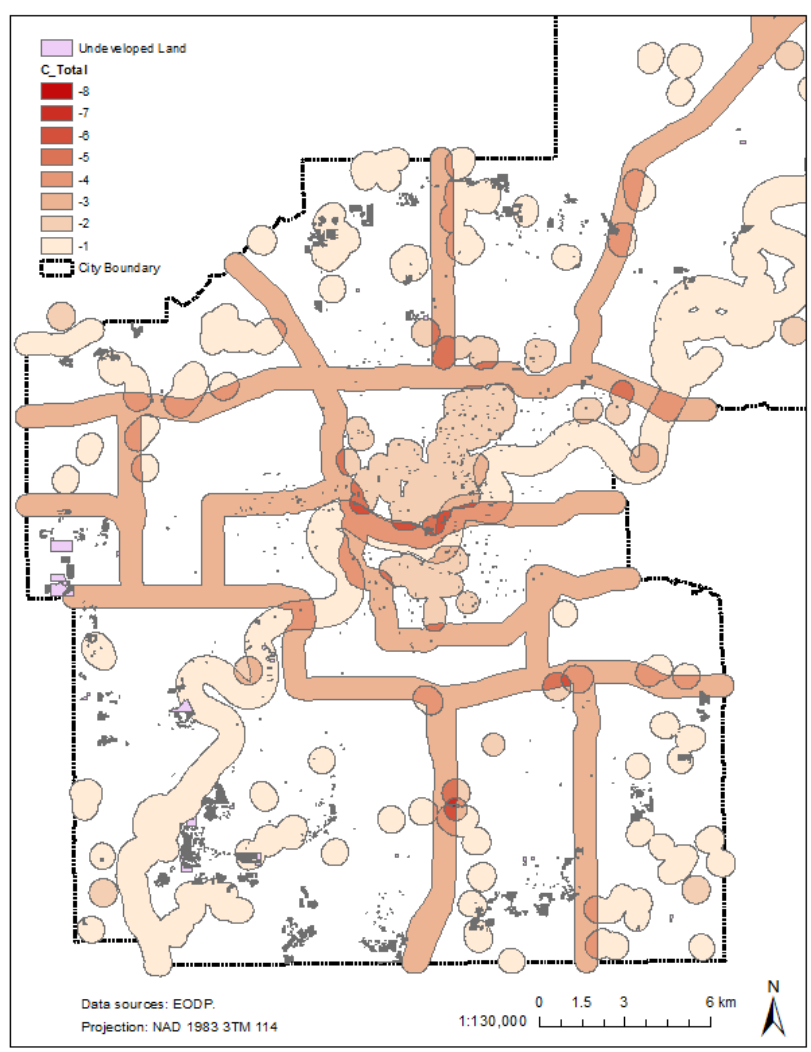

Figure 4. Distribution of constraint buffers.

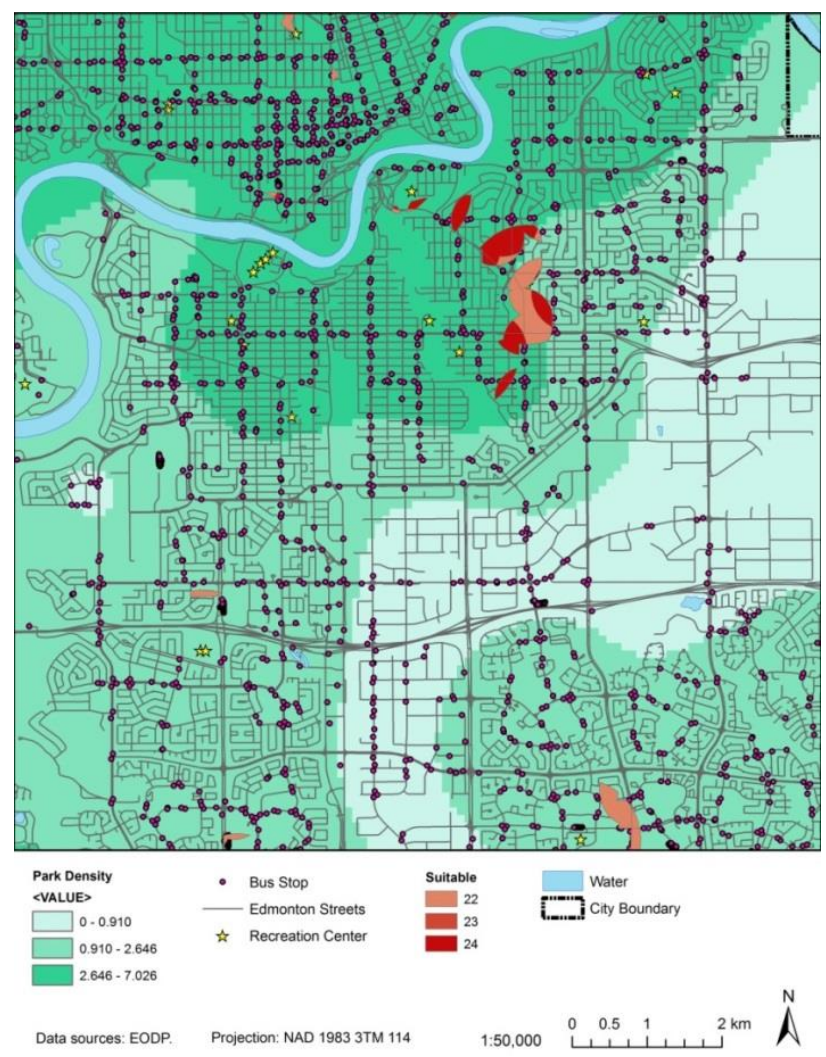

Figure 5. The suitable locations for developing panelized housing for seniors. 


\section{Discussion}

From the proposed methodology, location selection for panelized housing for seniors is influenced by selecting opportunities and constraints, as well as setting their weights and distance thresholds. Due to the availability of data, the number of opportunities and constraints selected in this study is relatively limited, and would likely not satisfy the demands of all the stakeholders. Meanwhile, because the weights can be subjective, different participants may provide different weights, which also influences location selection. The distance thresholds are derived from related regulations and expert opinions. These criteria can get more rigorous, if the areas neighbouring senior housing are expected to become more age-friendly. Additionally, more rigorous criteria will result in a decrease in the number of locations suitable for developing panelized housing for seniors.

\section{CONCLUSION}

Population ageing has become an unprecedented challenge that a majority of countries has been confronted with. Panelized construction, as a new technique, has the potential to boost the market share of senior housing in both an affordable and time efficient enough manner to satisfy the increasing demand. In fact, appropriate housing and access to facilities and services can influence seniors' independence and quality of life. Therefore, this paper uses GIS as the main tool to explore the potential locations for developing panelized housing for seniors from the perspective of accessibility, which integrates accessibility measure and suitability analysis. The proposed methods are then applied to developing panelized housing for seniors in the City of Edmonton, Canada. This application can facilitate accessibility analysis of senior housing for different stakeholders including urban planners, policy makers, developers, and seniors from the spatial perspective, and also lead to location selection for senior home development in order to enhance mobility independence and quality of life of older adults.

\section{ACKNOWLEDGEMENT}

This work was supported by the Tianjin Municipal Science and Technology Commission [grant number 17ZLZDZF00440] and Alberta Innovates.

\section{REFERENCES}

Alberta Health Services (AHS) (2018). "EMS: saving lives, improving care." $A H S$, <http://www.albertahealthservices.ca/ems/ems.aspx> (Sep. 30, 2018).

Balaguer, C., Abderrahim, M., Navarro, J.M., Boudjabeur, S., Aromaa, P., Kahkonen, K., Slavenburg, S., Seward, D., Bock, T., Wing, R., and Atkin, B. (2002). "FutureHome: An integrated construction automation approach." IEEE robotics \& automation magazine, 9(1), 55-66.

Bock, T. (2015). "The future of construction automation: Technological disruption and the upcoming ubiquity of robotics." Automation in Construction, 59, 113-121.

Boeing, G., Church, D., Hubbard, H., Mickens, J., and Rudis, L. (2014). "LEED-ND and Livability Revisited.” Berkeley Planning Journal, 27(1), 31-55. 
Chen, Y., Bouferguene, A., and Al-Hussein, M. (2018a). "Neighborhood design and regional accessibility of age-restricted communities from resilient and spatial perspectives." Proceedings, Construction Research Congress, 9-18.

Chen, Y., Bouferguene, A., Shen, Y., and Al-Hussein, M. (2018b). "Difference analysis of regional population ageing from temporal and spatial perspectives: a case study in China." Regional Studies, 1-12.

Edmonton's Open Data Portal (EODP). (2018). "Open data portal." City of Edmonton, $<$ https://data.edmonton.ca/> (Sep. 30, 2018).

El-Geneidy, A., Levinson, D., Diab, E., Boisjoly, G., Verbich, D., and Loong, C. (2016). "The cost of equity: Assessing transit accessibility and social disparity using total travel cost." Transportation Research Part A: Policy and Practice, 91, 302-316.

Frank, J.S. and Patla, A.E. (2003). "Balance and mobility challenges in older adults: implications for preserving community mobility." American journal of preventive medicine, 25(3), 157163.

Hansen, W.G. (1959). "How accessibility shapes land use." Journal of the American Planning Institute, 25(2), 73-76.

Koenig, J.G. (1980). "Indicators of urban accessibility: theory and application." Transportation, $9(2), 145-172$.

Li, H.X., Zhang, L., Mah, D., and Yu, H. (2017). "An integrated simulation and optimization approach for reducing $\mathrm{CO}_{2}$ emissions from on-site construction process in cold regions." Energy and Buildings, 138, 666-675.

Liu, H., Altaf, M. S., Lei, Z., Lu, M., and Al-Hussein, M. (2015). "Automated production planning in panelized construction enabled by integrating discrete-event simulation and BIM." Proceedings, International Construction Specialty Conference, 048, 1-10.

Saaty, T.L. (1977). "A scaling method for priorities in hierarchical structures." Journal of Mathematical Psychology, 15(3), 234-281.

City of Edmonton (2010). Edmonton seniors: A portrait. Edmonton, AB, Canada.

U.S. Green Building Council. (2016). "LEED v4 for neighborhood development." U.S. Green Building Council, <http://www.usgbc.org/resources/leed-v4-neighborhood-developmentcurrent-version> (July 1, 2009).

World Health Organization (WHO) (2007). Global Age-Friendly Cities: A Guide. Geneva, Switzerland. 